\title{
Selective Effects of D- and L-Govadine in Preclinical Tests of Positive, Negative, and Cognitive Symptoms of Schizophrenia
}

\author{
Christopher C Lapish*,', Kee-Chan Ahn², R Andrew Chambers ${ }^{3}$, Donovan M Ashby ${ }^{2}$, Soyon Ahn ${ }^{2}$ and \\ Anthony G Phillips ${ }^{2}$
}

'Department of Psychology, Indiana University-Purdue University Indianapolis, Indianapolis, IN, USA; ${ }^{2}$ Department of Psychiatry, University of British Columbia, Vancouver, BC, Canada; ${ }^{3}$ Department of Psychiatry, Indiana University School of Medicine, Indianapolis, IN, USA

\begin{abstract}
There is a critical need to develop novel pharmacotherapeutics capable of addressing the positive, negative, and cognitive symptoms of schizophrenia. Building on recent studies with a racemic mixture of the synthetic tetrahydroprotoberberine, D,L-Govadine, we isolated the D- and L-stereoisomers and employed a battery of behavioral, neurochemical, and electrophysiological procedures to assess their individual therapeutic potential. Rodent models predictive of antipsychotic efficacy and those that model positive symptoms were employed and we found that L-Govadine, but not D-Govadine, improved these measures. Pretreatment with either stereoisomer during CS pre-exposure prevented the disruption of latent inhibition by amphetamine. Moreover, pretreatment with either stereoisomer also improved deficits in social interaction in the neonatal ventral hippocampal lesioned rat. Improved cognitive performance in two different prefrontal cortexdependent tasks was observed with D-, but not L-Govadine, which strongly suggests that the D-steroisomer may be an effective cognitive enhancer. Alterations in dopamine efflux were also assessed and L-Govadine increased dopamine efflux in both the prefrontal cortex and nucleus accumbens. However, D-Govadine only increased dopamine efflux in the prefrontal cortex and not in the nucleus accumbens. Electrophysiological studies confirmed that L-Govadine is a DA-D2 antagonist, whereas D-Govadine shows no appreciable physiological effects at this receptor. Collectively these data show that L-Govadine performs well on measures predictive of antipsychotic efficacy and rodent models of positive symptoms through antagonism of DA-D2 receptors, whereas D-Govadine improves impairments in compromised memory function in delayed response tasks possibly through selective increases in DA efflux in the frontal cortex. Neuropsychopharmacology (2014) 39, 1754-1762; doi:I0.1038/npp.2014.23; published online 26 February 20I4
\end{abstract}

Keywords: schizophrenia; cognitive enhancer; antipsychotic; dopamine; neonatal ventral hippocampal lesioned rat; microdialysis

\section{INTRODUCTION}

The positive symptoms of schizophrenia respond well to treatment with both typical and atypical antipsychotic drugs, which is attributable to their shared property as dopamine (DA) D2 antagonists (Kapur et al, 2006). Unfortunately, drugs that effectively manage negative and cognitive symptoms are still forthcoming. This is a particularly urgent issue as impaired cognitive function is a core symptom of schizophrenia (Andreasen, 2000; Freedman, 2003) and improvements in this domain are particularly strong predictors of positive treatment outcomes and social reintegration (Hofer et al, 2011; Uggerby et al, 2011).

A growing body of preclinical evidence has focused interest on tetrahydroprotoberberines (THPB), including L-Stepholidine (L-SPD), in the treatment of schizophrenia

\footnotetext{
* Correspondence: Dr Christopher C. Lapish, Department of Psychology, Indiana University-Purdue University Indianapolis, LD 124, $402 \mathrm{~N}$. Blackford St, Indianapolis, IN 46202-3275, USA, Tel: +317 2746931 , Fax: +317 274 6756, E-mail: clapish@iupui.edu Received 16 July 2013; revised 22 October 2013; accepted 7 January 2014; accepted article preview online 30 January 2014
}

and Parkinson's disease (Jin et al, 2002; Natesan et al, 2008). L-SPD has a unique neuropharmacological profile as a D1 agonist and D2 antagonist (Dong et al, 1997). D1 receptors have a critical role in modulating executive function in the medial prefrontal cortex and D1 agonists have been proposed as promising candidates for ameliorating cognitive deficits associated with schizophrenia (Goldman-Rakic et al, 2000, 2004). Recently, we reported that the racemic THPB, D,L-Govadine (D,L-GOV), performed well on a number of preclinical behavioral measures predictive of efficacy in the treatment of positive and cognitive symptoms (Lapish et al, 2012). Of particular interest in these previous studies was an increase in DA efflux in the PFC evoked by D,L-GOV, along with improvements in a memoryguided foraging task linked to optimal DA function in the PFC (Seamans et al, 1998).

Subsequent to these initial experiments with D,L-GOV, a chiral separation procedure was developed that yielded the stereoisomers, D-Govadine (D-GOV) and L -Govadine (L-GOV) (Zhai et al, 2012). Although stereoisomer-specific formulations may have similar functional properties (Ferrari et al, 1995), often each stereoisomer can display distinct pharmacological properties (Bingham et al, 2007; 
Robaa et al, 2011). Stereo-specific formulations of drugs with proven pharmacological efficacy can improve therapeutic outcomes via reduced side effects and more accurate dosing (Agranat and Caner, 1999; De Camp, 1989). As such, the FDA and EMEA have encouraged the development of stereoisomer formulations (De Camp, 1989). The improved safety and efficacy conferred by stereo-specific formulations, coupled with our preclinical data indicating the possible efficacy of D,L-GOV on tests of both positive symptoms and cognitive deficits, motivated a comprehensive analysis of the behavioral, neurochemical, and electrophysiological properties of D-GOV and L-GOV. This report identifies unique, yet complementary, actions of each isomer and provides compelling preclinical evidence for their antipsychotic, prosocial, and possibly procognitive properties.

\section{MATERIALS AND METHODS}

All procedures conformed to the guidelines outlined by the Canadian Council on Animal Care and the National Institutes of Health Guide for the Care and Use of Laboratory Animals and were approved by the the Institutional Animal Use and Care Committee at IUPUI. All procedures were performed in male Long Evans rats unless otherwise noted.

\section{Receptor Binding}

The affinity of D-GOV and L-GOV for DA, serotonin, and noradrenaline receptors were assessed (see Supplementary Information) by MDS Pharma Services (King of Prussia, PA).

\section{Behavior}

In depth descriptions of each behavioral task can be found in the Supplementary Material.

Amphetamine-induced locomotion (AIL) was assessed for $1 \mathrm{~h}$ in a dimly lit open field following administration of an intraperitoneal injection of D-AMPH $(1.5 \mathrm{mg} / \mathrm{kg})$. Fifteen min before the D-AMPH injections, animals received subcutaneous (SC) injections of vehicle, D-GOV, L-GOV, or clozapine.

Catalepsy was assessed after a SC injection of vehicle, DGOV, or L-GOV. The cumulative time spent with forelimbs immobilized on a horizontal bar was scored over a 2-min period beginning $1,15,30$, and 45 min after injection.

Conditioned avoidance responding (CAR) was assessed in animals that demonstrated proficiency in a two-way avoidance Pavlovian conditioning paradigm, evidenced by an association between the conditioned stimulus (CS; white noise, $\sim 60 \mathrm{~dB}$ ) and unconditioned stimulus (US; footshock, $0.75 \mathrm{~mA}$ ) that, with repeated pairing, led to an avoidance response after presentation of the CS. One day after demonstrating a clear association between the CS and US, pharmacological testing occurred. On the test day animals received SC injections of vehicle, D-GOV, L-GOV, or clozapine $15 \mathrm{~min}$ before CAR was assessed for $100 \mathrm{CS}-\mathrm{US}$ pairings.

Latent inhibition (LI) experiments were designed to examine whether treatment with either D-GOV or L-GOV during the pre-exposure phase could suppress subsequent
D-AMPH-induced disruptions in LI. On the pre-exposure days animals received injections of vehicle $\mathrm{D}-\mathrm{GOV}(1.0 \mathrm{mg} / \mathrm{kg}$ $\mathrm{SC}$ ) or L-GOV (1.0 mg/kg SC). On the day of conditioning, LI was assessed in a two-way avoidance Pavlovian conditioning paradigm identical to the CAR procedure used. LI was confirmed as a reduction in the number of avoidances during the CAR test in animals pre-exposed to the CS compared with those exposed to the CS for the first time. This experiment also included treatment with D-AMPH $(1.0 \mathrm{mg} / \mathrm{kg})$ or saline vehicle, $45 \mathrm{~min}$ before behavioral testing to examine the effects of D-GOV or L-GOV during CS preexposure on D-AMPH-induced disruption of LI. CAR acquisition consisted of 100 CS-US pairings.

Social interaction (SI) was assessed in male Sprague Dawley rats as described in (Truitt et al, 2009). Neonatal ventral hippocampal lesioned (NVHL) and sham-lesioned (Shams) rats were prepared as described in (Chambers et al, 2010). For detailed methods see Supplementary Information. Briefly, on the day of SI testing, rats in both the NVHL and Sham groups were injected with either vehicle D-GOV (1.0 mg/kg SC) or L-GOV (1.0 mg/kg SC) $15 \mathrm{~min}$ before SI testing. The cumulative time spent by each rat with its head oriented closely toward or in contact with the conspecific animal was scored as SI.

Temporal order recognition memory was measured as the preference of an animal to explore a location on an eightarm maze visited more remotely in time $v s$ an arm visited more recently and was performed as described in (Hannesson et al, 2004). Briefly, 15 min before the memory test that took place either $60 \mathrm{~min}$ or $240 \mathrm{~min}$ after exploring the second pair of arms, rats were injected with vehicle, D-GOV (1.0 mg/kg SC), L-GOV (1.0 mg/kg SC), or clozapine $(5.0 \mathrm{mg} / \mathrm{kg} \mathrm{SC})$. Time spent in each location (recent and remote), total distance traveled, and the total number of entries into each location were scored from video recordings off-line (see Supplementary Information).

Prospective working memory was assed by a spatial winshift task using a radial-arm maze (Seamans et al, 1998). Rats were maintained at $85 \%$ target body weight and trained to identify blocked arms that would subsequently contain food after a delay period once food was obtained from six open arms during the training phase. After a 1-min delay, each rat was returned to the radial-arm maze with all eight arms open. Memory for the correct arms, the two yet to be visited that still contained food, was assessed to a criterion of $<2$ errors on two consecutive days. After reaching this criterion, animals were tested at a longer delay of $15 \mathrm{~min}$. Before these test trials, rats received counterbalanced injections of vehicle, D-GOV ( $1.0 \mathrm{mg} / \mathrm{kg} \mathrm{SC})$, L-GOV $(1.0 \mathrm{mg} / \mathrm{kg} \mathrm{SC}) 15 \mathrm{~min}$ before the training phase. Errors were scored as test-phase entries into arms visited previously.

\section{Microdialysis}

Procedures were identical to those described in (Lapish et al, 2012), but see Supplementary Information. Once baseline levels of DA efflux were stable, counterbalanced injections of vehicle/D-GOV (1.0 mg/kg SC) or vehicle/L-GOV $(1.0 \mathrm{mg} / \mathrm{kg}$ SC) were administered. Microdialysis samples were collected every $10 \mathrm{~min}$ and analyzed immediately using high-pressure liquid chromatography with electrochemical detection. 


\section{Electrophysiology}

To determine the effects of each isomer on ventral tegmental area DA neuron firing, electrophysiological experiments were performed in an acute slice preparation. Briefly, male Sprague Dawley rats (3-5 weeks old) were decapitated under halothane anesthesia and the brain was rapidly removed and placed in ice-cold cutting solution. Midbrain slices $(220 \mu \mathrm{m})$ were prepared using a vibratome and then incubated for $>1 \mathrm{~h}$ at room temperature in physiological saline. DA neurons were identified by spontaneous pacemaker firing $(1-3 \mathrm{~Hz})$ with broad APs $(\geqslant 2.0 \mathrm{~ms}$ ) (Ahn et al, 2010). Cells not responding to Quinpirole (500 nM) were excluded. Cells were also filled with Alexa or Neurobiotin for post-hoc identification using tyrosine hydroxylase immunostaining (see (Gorelova et al, 2012) for staining methods). Whole-cell voltage clamp recordings (holding potential, $V \mathrm{~h}$, set at $-60 \mathrm{mV}$ ) were made using Sigma-coated pipettes with resistance of 5-7 M . All electrophysiological measurements were obtained with an EPC-9 patch-clamp amplifier controlled by Tida software (HEKA Electronik, Lambrecht, Germany). All drugs including $\mathrm{L}-$ or $\mathrm{D}-\mathrm{Govadine}(10 \mathrm{nM}$ to $10 \mu \mathrm{M})$ were bath-applied.

\section{RESULTS}

\section{Receptor Binding}

Both D-GOV and L-GOV exhibited higher affinity for DA-D ${ }_{1} /$ $D_{5}$ receptors $(<10 \mathrm{nM})$ as compared with $D A-D_{2 L}$ receptors (165 nM). Modest affinity for adrenergic receptors, and low affinity for serotonin receptors was also observed (Figure 1a).

\section{Amphetamine-Induced Locomotion}

A dose-dependent attenuation of AIL was observed with L-GOV treatment, but not D-GOV, even at a dose of $10.0 \mathrm{mg} / \mathrm{kg}$ (main effect of treatment, one-way ANOVA, $\mathrm{F}(11,65)=25.47$, $P<0.0001)$. Both doses of CLZ completely suppressed AIL to levels that did not differ significantly from saline $+\mathrm{VEH}-$ treated animals (Figure 1b).

\section{Catalepsy}

Catalepsy was induced in a dose-dependent manner by L-GOV, but not D-GOV, (dose $\times$ time interaction, two-way ANOVA, $\mathrm{F}(20,149)=10.64, P<0.0001$, Figure 1c). Minimum levels of catalepsy were observed with a dose of $1.0 \mathrm{mg} / \mathrm{kg} \mathrm{L-GOV}$. Catalepsy peaked at $15 \mathrm{~min}$ post treatment with L-GOV (Figure 1c, inset).

\section{Conditioned Avoidance Responding}

A dose-dependent decrease in CAR was observed with L-GOV but not D-GOV (main effect of treatment, one-way ANOVA $\mathrm{F}(3,104)=4.4, P<0.01)$. Pretreatment with CLZ $(5.0 \mathrm{mg} / \mathrm{kg})$ produced a small but significant decrease in avoidance responses. Animals that exhibited a decreased number of avoidances following drug treatment usually escaped from the US (treatment $\times$ measure interaction, twoway ANOVA, $\mathrm{F}(3,104)=31.48, P<0.0001)$, confirming that neither L-GOV nor CLZ treatment produced an overt motor impairment at doses that disrupted CAR (Figure 1d).

\section{Latent Inhibition}

LI was assessed initially in rats treated with either saline or $1.0 \mathrm{mg} / \mathrm{kg}$ D-AMPH on the test day (Figure 1e). Animals that were given $\mathrm{VEH}$ before CS pre-exposure and then treated with saline on the test day made significantly fewer avoidance responses compared with the NPE group receiving the same treatment, which is consistent with a LI effect (main effect of CS-exposure, two-way ANOVA, $\mathrm{F}(1,84)=17.5, P<0.001)$. Rats treated with VEH during the $\mathrm{CS}$ pre-exposure period and then given $\mathrm{D}-\mathrm{AMPH} 1 \mathrm{~h}$ before the CAR test, did not exhibit LI, thereby replicating the commonly observed disruptive effect of a psychostimulant on LI (Moser et al, 2000; Weiner et al, 2003). Treatment with either L-GOV or D-GOV during CS pre-exposure prevented disruption of LI in animals given D-AMPH before conditioning (exposure $\times$ treatment interaction, two-way ANOVA, $\mathrm{F}(1,31)=5.73, P<0.05$; Figure $1 \mathrm{e})$.

\section{Social Interaction}

Vehicle-treated rats in the NVHL group exhibited a marked decrease in SI time (Bonferroni corrected planned comparison, $t(30)=3.124, P<0.01$; Figure 2). This effect was reversed by treatment with either $\mathrm{D}-\mathrm{GOV}$ or L-GOV, with comparable levels of SI observed in NVHL and Sham control groups.

\section{Electrophysiology}

Firing rates of confirmed DA neurons (Figure 3a), averaged over the last $3 \mathrm{~min}$ of a 10 -min recording period were suppressed by bath application of the D2 agonist Quinprole and this effect was reversed by bath application of L-GOV, but not $\mathrm{D}-\mathrm{GOV}$, (time $\times$ treatment interaction, two-way repeated measures ANOVA, $\mathrm{F}(2,6)=15.238, P<0.001$, Figure $3 \mathrm{~b}$ and $\mathrm{c}$ ). The suppression of $\mathrm{DA}$ neuron firing was mediated by G-coupled inward rectifying $\mathrm{K}^{+}$(GIRK) channels, as bath application of the GIRK blocker, tertiapin, blocked the quinprole-mediated increase in outward currents (Figure 3d and e). The Quinprole effect was unaltered by bath application of the GABAB antagonist, Baclofen, indicating that $\mathrm{GABAB}$ currents were not involved in the observed inhibition of firing in DA neurons (Supplementary Figure 4).

\section{Microdialysis}

Peripheral administration of $\mathrm{D}-\mathrm{GOV}$ increased DA efflux in the PFC (treatment $\times$ time interaction, two-way ANOVA, $\mathrm{F}(18,228)=1.71, \quad P<0.05$, Figure 4a) but not in the NAc (treatment $\times$ time interaction, two-way ANOVA, $\mathrm{F}(18,209)=0.14, P>0.05$, Figure $4 \mathrm{~b})$, relative to the VEH condition. Increases in the efflux of DA metabolites were also observed selectively in the PFC (Supplementary Figures 2 and 3). L-GOV increased DA efflux in both the PFC (treatment $\times$ time interaction, two-way ANOVA, $\mathrm{F}(18,228)=1.87, \quad P<0.05$, Figure $4 \mathrm{c})$ and in the NAc 
a

\begin{tabular}{lcc}
\hline & D-GOV & L-GOV \\
\hline Receptor & Affinity & $(K i, \mathrm{nM})$ \\
\hline $\mathrm{D}_{1}$ & 8.75 & 5.77 \\
$\mathrm{D}_{2 \mathrm{~L}}$ & 1340 & 165 \\
$\mathrm{D}_{2 \mathrm{~S}}$ & 708 & 514 \\
$\mathrm{D}_{3}$ & 606 & 548 \\
$\mathrm{D}_{5}$ & 13.4 & 10.5 \\
$\alpha_{1 \mathrm{~A}}$ & 648 & 369 \\
$\alpha_{1 \mathrm{~B}}$ & 2590 & 2480 \\
$\alpha_{1 \mathrm{D}}$ & 263 & 235 \\
$\alpha_{2 \mathrm{~A}}$ & 304 & 223 \\
$5-\mathrm{HT}_{1 \mathrm{~A}}$ & 18200 & 15200 \\
$5-\mathrm{HT}_{2 \mathrm{~A}}$ & 11800 & 11100 \\
$5-\mathrm{HT}_{2 \mathrm{C}}$ & 46500 & 45200 \\
\hline
\end{tabular}

C

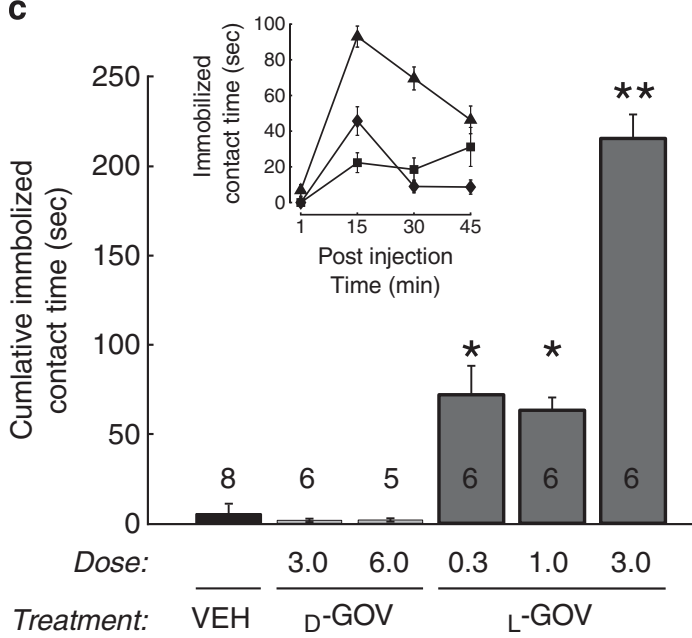

b

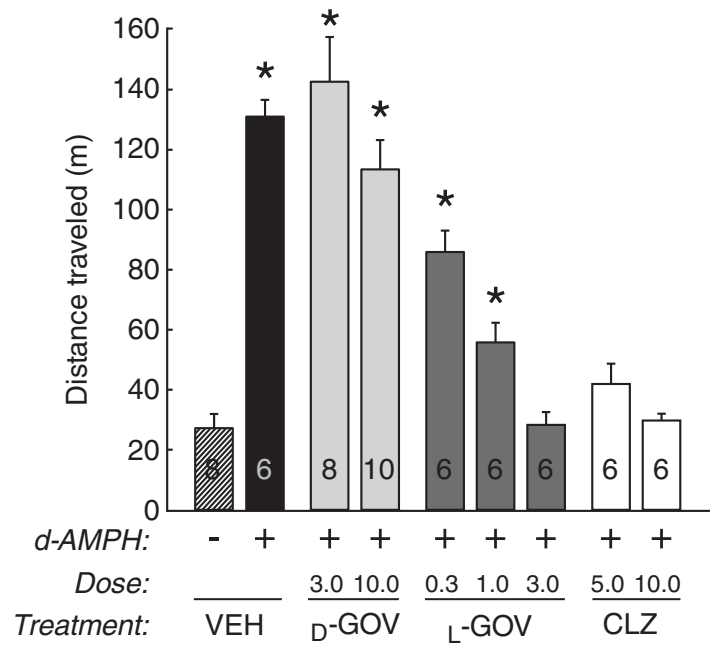

d

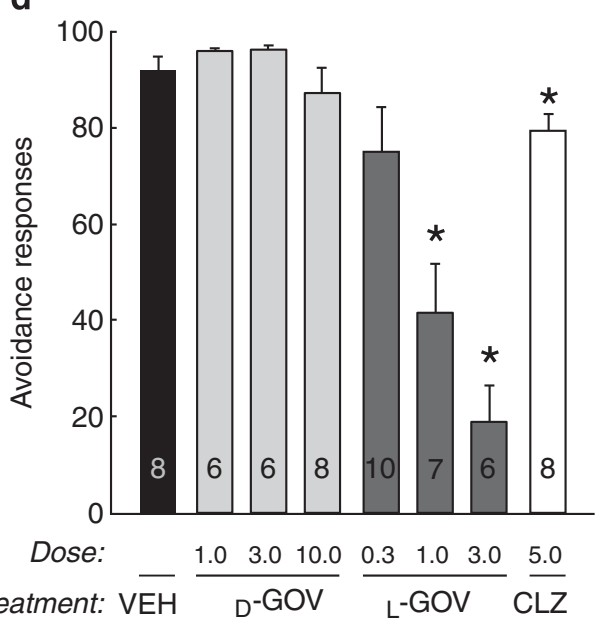

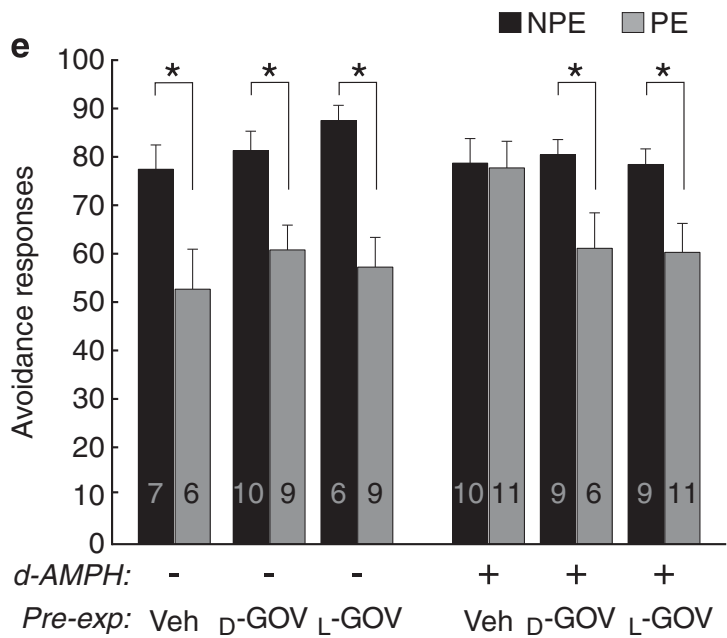

Figure I (a) Receptor-binding affinity (in nM) for dopamine, noradrenalin, and serotonin receptors. (b) Effects of D-GOV (light gray bars), L-GOV (dark gray bars), or CLZ (white bars) on D-AMPH-induced locomotion (black bar). (c) Cataleptic effects of L-GOV but not D-GOV. (d) Effects of D-GOV (light

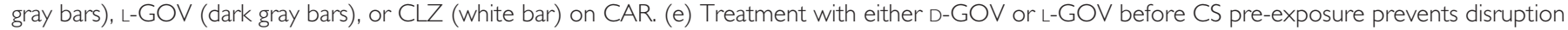

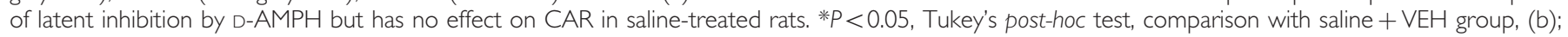
$* P<0.05$, ** $P<0.0$ I comparison with VEH group ( $c$ and $d$ ); and * $P<0.05$, Tukey's post-hoc test (e). 


\section{a}

\section{Sham}

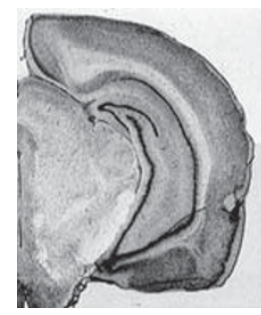

NVHL

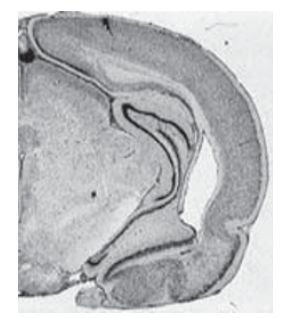

b

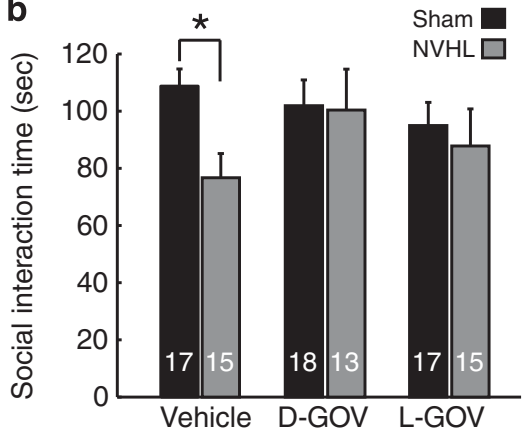

Figure 2 (a) Photomicrographs from representative animals that received a neonatal ventral hippocampal lesion (NVHL) or a sham lesion (SHAM). (b) Effects of D-GOV or L-GOV on social interaction time displayed by rats with NVHL (gray bars) or sham controls (black bars). *P<0.05, planned comparison.

a

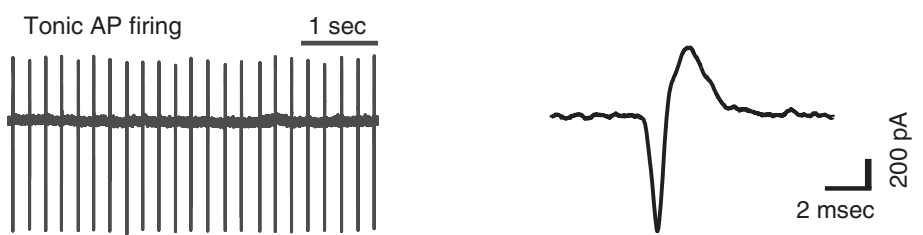

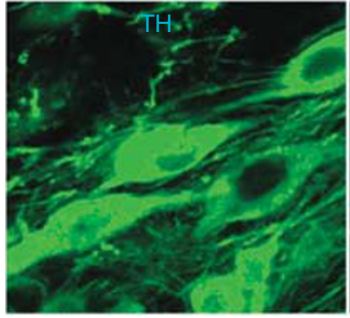

b

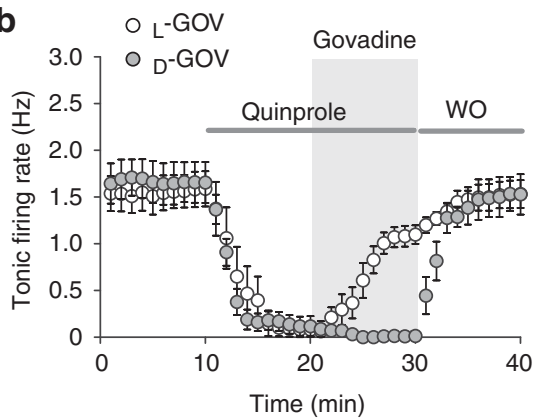

d

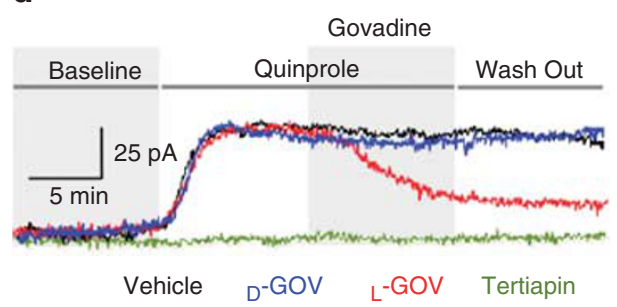

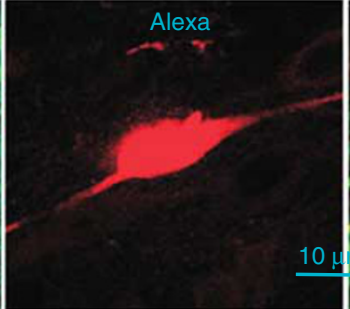

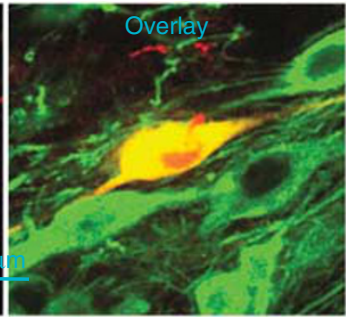

C
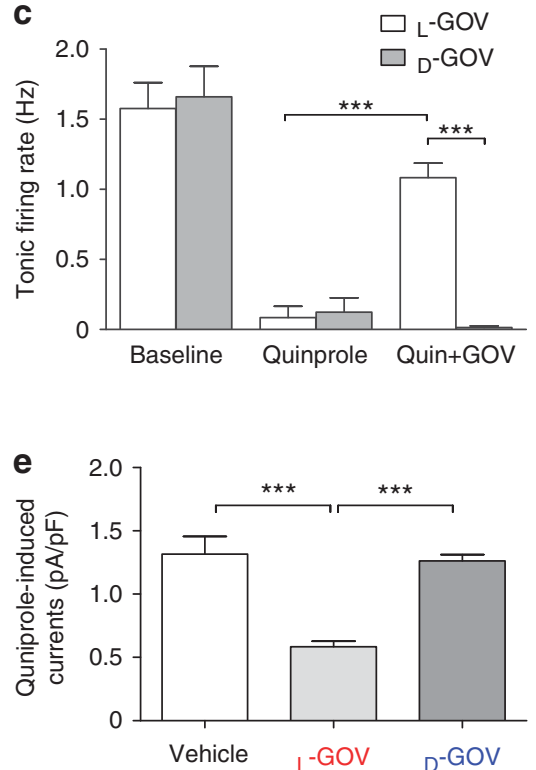

Figure 3 (a, top left) Traces of action potentials from a DA neuron and (a, top right) a single action potential displayed on an expanded time scale. (a, bottom) Immunoreactivity for tyrosine hydroxylase was verified at the end of experiments in all electrophysiologically identified midbrain DA neurons filled with Alexa. (b) Summary time graphs illustrating the effects of L-GOV (I $\mu \mathrm{M})$ (white circle) and D-GOV (I $\mu \mathrm{M}$ ) (gray circle) on D2-mediated basal firing inhibition. Co-application of L-GOV, but not D-GOV, during the peak inhibitory effect of Quinpirole (500 nM), antagonized the D2 autoreceptor-mediated decreases in basal tonic firing of DA neurons. (c) Summary bar graphs show that L-GOV $(n=6)$, but not D-GOV $(n=5)$, restored basal firing rates up to $70 \%$ of pre-baseline values measured before Quinpirole-induced inhibition. (d) Quinpirole ( $500 \mathrm{~nm}$ ) initially activated G-protein-gated inwardly rectifying K ${ }^{+}$(GIRK) channels without vehicle influence (black), and subsequent co-application of L-GOV (red), but not D-GOV (blue), suppressed the GIRK activity. Pretreatment with Tertiapin-Q (500 nm), a Kir I.I/3.I blocker, completely eliminated the GIRK outward currents induced by Quinpirole (green). (e) Summary bar graphs depicting that L-GOV, but not D-GOV, reduced GIRK-mediated currents. **** $P<0.00$ I, Holm-Sidak (c) and Tukey's (e) post-hoc test. 

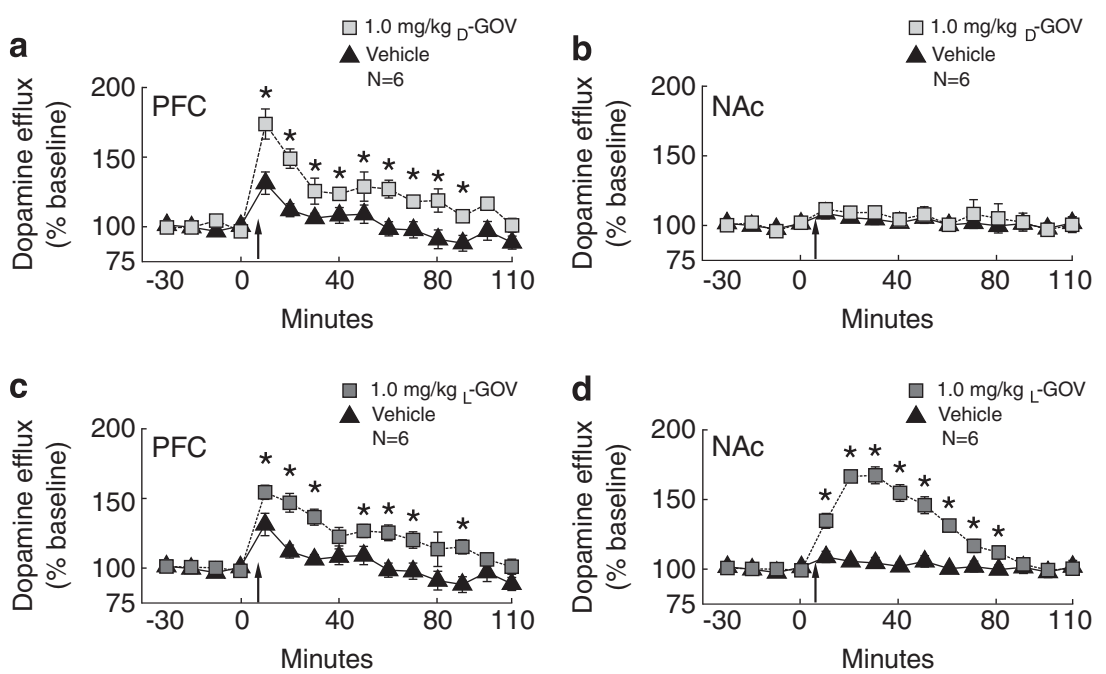

Figure 4 D-GOV (I.0 mg/ $/ \mathrm{kg}$ ) increased dopamine in the PFC (a) but not in the NAc (b). L-GOV (I.0 mg/kg) increased dopamine efflux in both the PFC (c) and the NAc (d). ${ }^{*} P<0.05$, Tukey's post-hoc test, comparison between vehicle and GOV groups.

(treatment $\times$ time interaction, two-way ANOVA, $\mathrm{F}(18,209)=$ $19.5, P<0.001$, Figure $4 \mathrm{~d})$ relative to the VEH condition.

\section{Temporal Order Recognition Memory (TORM)}

VEH-treated rats displayed TORM in the present study by spending more time in an arm visited in the first phase of training, as compared with an arm visited in the second phase of training $45 \mathrm{~min}$ earlier (Figure 5a1). TORM was disrupted in the VEH-control group by the imposition of a 240-min delay between the second phase of training and the memory test (Figure 5a2). Treatment with either L-GOV or CLZ disrupted TORM following the 45-min delay (Figure 5a1) but had no effect on TORM after an extended 240-min delay (Figure 5a2). D-GOV given before a recall test disrupted TORM after the 45 -min delay, as rats in this condition failed to show a preference for the arm visited more remotely in time (Figure 5a1). In contrast, treatment with D-GOV before a recall test after a 240-min delay restored the preference for the arm visited more remotely in time, consistent with restitution of TORM (D-GOV and VEH groups, treatment $\times$ delay $\times$ arm interaction, factorial ANOVA, $\mathrm{F}(1,36)=4.56, P<0.05)$. D-GOV treatment before the 45-min delay increased the distance traveled (main effect of treatment, one-way ANOVA, $\mathrm{F}(3,42)=29.87, P<0.001)$ and the number of arm entries (main effect of treatment, one-way ANOVA, $\mathrm{F}(3,42)=12.47, P<0.01)$ during TORM testing (Supplementary Table 1). When retested after a 240-min delay, rats treated with either L-GOV or CLZ moved less and made fewer arm entries compared with the D-GOV or VEH groups (Tukey's post-hoc test, $P<0.05$ ), which is consistent with the motor augmenting/sedative effects typically observed with D2 antagonists (Fibiger et al, 1976). However, no significant differences were observed in distance traveled or arm entries between D-GOV or VEH groups after the 240-min delay (Tukey's post-hoc test, $P>0.05)$ ruling out changes in locomotor activity as responsible for the restoration of TORM.

\section{Delayed Win-Shift Following a 15-min Delay}

Rats treated with D-GOV, but not L-GOV, displayed a significant improvement in selection of arms that were previously blocked during the training phase and baited with food following a 15-min delay (Figure 5b). This was reflected in a decrease in test-phase errors (Bonferroni corrected planned comparison, D-GOV $t(6)=-3.873$, $P<0.01 ;$ L-GOV $t(6)=0.8911, P>0.05)$.

\section{DISCUSSION}

The present study confirms efficacy on preclinical tests of positive symptoms of schizophrenia following treatment with L-GOV and to a lesser extent with D-GOV, whereas the improvement of impaired working memory and prospective memory are a property of D-GOV. Impaired SI is typically classified as a negative symptom and both isomers reversed the impaired phenotype in the NVHL rat, a validated preclinical model of schizophrenia (Tseng et al, 2009). Collectively, these findings, in conjunction with our previous work (Lapish et al, 2012), indicate that GOV in both its racemic form and as separate isomers may have the unique potential to address the three cardinal symptoms of schizophrenia.

A comparison of the receptor-binding profiles of each isomer reveals that both share a high affinity for the DA-D1/ D5 receptor family, whereas L-GOV has a much greater affinity for the DA-DA2 receptor compared with D-GOV. Each isomer also exhibits moderate affinity for noradrenaline receptors and low affinity for 5-HT receptors (Figure 1a). In functional binding assays reported previously, L-GOV reduces cAMP formation (Lapish et al, 2012). Our electrophysiological data, showing a complete reversal by L-GOV, but not D-GOV, of the D2 autoreceptor-mediated inhibition of spontaneous firing rates in identified DA neurons in VTA slices, are also consistent with the classification of L-GOV as a DA-D2 antagonist.

The pharmacological profile of L_GOV is consistent with previous studies outlining the DA-D2 antagonist action of the THPB, L-Stepholidine (L-SPD; Dong et al, 1997). 

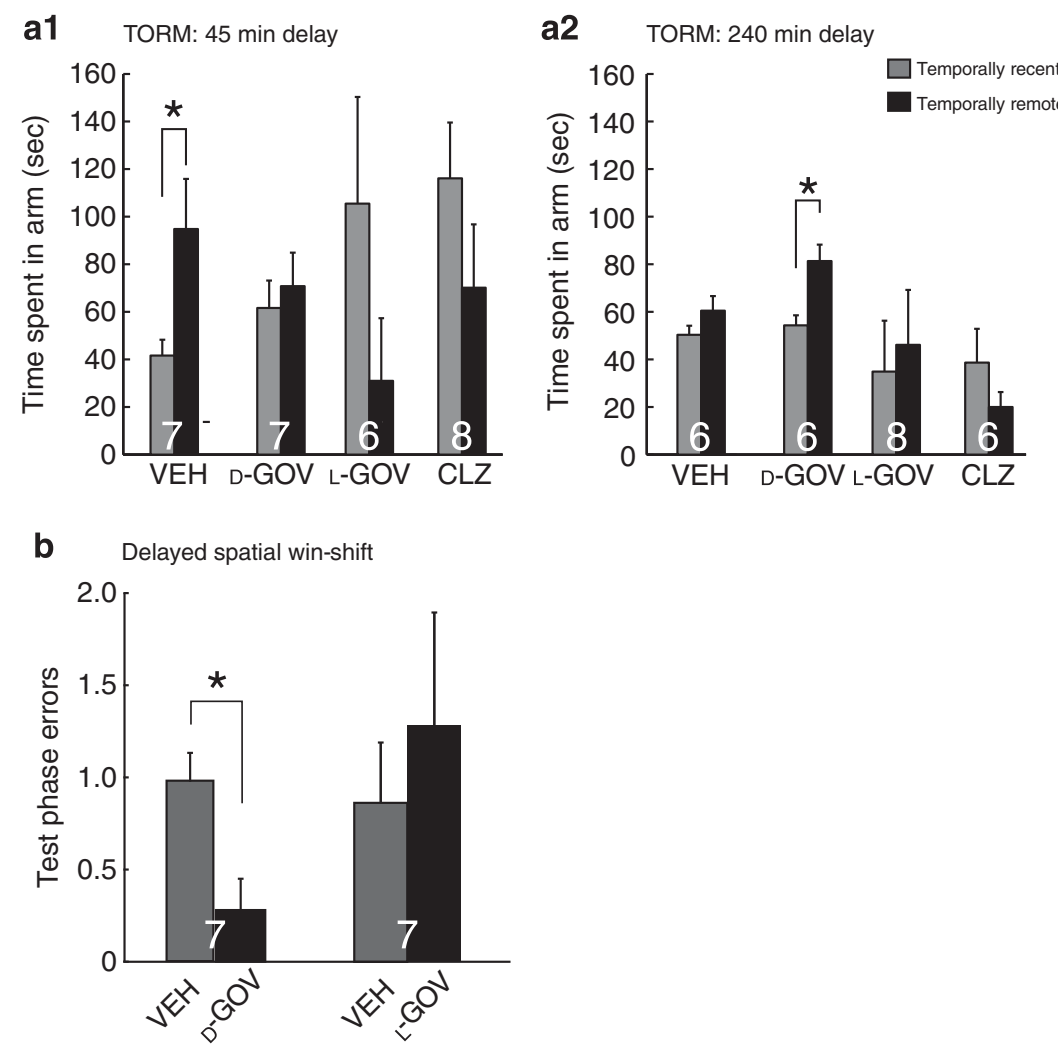

Figure 5 Effects of D-GOV (I.0 mg/kg), L-GOV (I.0 mg/kg), CLZ $(5.0 \mathrm{mg} / \mathrm{kg})$, or VEH on (a I) TORM at a 45-min delay or (a2) 240-min delay. At the 45-min delay, TORM was expressed in the VEH group and treatment with D-GOV, L-GOV, or CLZ impaired TORM. At the 240-min delay VEH, L-GOV, and CLZ groups did not exhibit TORM, but D-GOV restored TORM. (b) A decrease in test-phase errors of the delayed spatial win-shift was observed with D-GOV but not L-GOV. $* P<0.05$, Tukey's post-hoc test (al and a2) and $* P<0.05$, planned comparison b).

However, these data separate D-GOV and L-SPD on the basis of actions at the DA-D2 receptor by showing that D-GOV has low affinity and a behavioral profile inconsistent with D2 antagonist effects. Functional binding studies have established L-SPD to be a DA-D1 agonist (Natesan et al, 2008), however, no DA-D1 agonist activity could be detected with D-GOV pointing to another possibly important difference between these compounds.

As anticipated on the basis of the receptor-binding and electrophysiological data, L-GOV displayed positive effects on preclinical behavioral tests in rats predictive of antipsychotic efficacy. Specifically, L-GOV suppressed CAR and AIL in a dose-dependent manner (Figure 1b-d). Clear differences were observed between the isomers in these two classic tests of antipsychotic efficacy, as D-GOV had no effect on either CAR or AIL (Figure 1b-d), consistent with negligible binding or functional affinity at DA-D2 receptors (Figure 1; Lapish et al, 2012).

Typical antipsychotics exert a stronger effect on DA efflux in the ventral striatum than in the prefrontal cortex, whereas comparable increases in DA efflux are observed in both structures following treatment with atypical antipsychotics, including clozapine (Moghaddam and Bunney, 1990). Microdialysis experiments with D,L-GOV revealed a pattern of DA efflux that is consistent with atypical antipsychotics (Lapish et al, 2012). When this analysis is extended to the individual isomers of GOV, two striking patterns emerge. First, L-GOV similarly increased DA efflux in both the PFC and ventral striatum, consistent with atypical antipsychotic properties. Second, the effects of D-GOV on DA efflux are restricted to the mPFC. The mechanism for this unique ability to selectively enhance DA effux in the frontal cortex remains to be specified, but could lead to novel treatment strategies for hypodopaminergic function within this region of the cortex.

In contrast to these clear differences between D- and L-GOV, both isomers displayed similar effects on disruption of LI by D-AMPH. Reversal of psychostimulant-induced disruption of LI is interpreted as an analog of positive symptoms of schizophrenia reflecting an inability to classify environmental stimuli as irrelevant (Weiner and Feldon, 1997). In the present study, pretreatment with either isomer before CS pre-exposure sessions prevented the subsequent disruption of LI by D-AMPH (Figure 1e). Importantly, treatment with D- or L-GOV during CS pre-exposure had no effect on LI in the control group given saline before the acquisition of CAR. These data replicate and extend our previous findings with D,L-GOV (Lapish et al, 2012). The fact that GOV, in both the racemic form or as separate isomers, does not alter the expression of LI in saline-treated animals, but prevents D-AMPH from disrupting LI suggests that pretreatment with GOV may facilitate recall of the CS on the day of conditioning. This effect could also reflect an influence of GOV on sensory filtering, which is thought to be impaired in schizophrenia (Bunney et al, 1999), and may serve as an important predictor of antipsychotic efficacy. 
The NVHL models many of the behavioral and biological abnormalities observed in schizophrenia, and is regarded as a valid neurodevelopmental model of this condition (Tseng et al, 2009). Social withdrawal and isolation are the commonly observed negative symptoms of schizophrenia and are effectively modeled in the NVHL as deficits in SI (Sams-Dodd et al, 1997). We find that pretreatment with either isomer of GOV restored SI times to levels observed in control animals (Figure 2) suggesting that negative symptoms may be treated effectively by either isomer of GOV. This is also supported by our previous finding that pretreatment with racemic GOV mitigates enhanced LI in rats sensitized to d-AMPH (Lapish et al, 2012), which has been proposed as a rodent model of negative symptoms (Weiner and Arad, 2009).

Impairments in cognitive functions are hallmarks of schizophrenia attributed, in part, to hypofunction of the PFC DA system (Goldman-Rakic et al, 2004). Correct identification of the temporal order in which events occurred is impaired in schizophrenics (Dreher et al, 2001) and can be assessed in rats via their preference for an object or location that was experienced more remotely in time. The capacity to display TORM is dependent on the integrity of the PFC and the DA system (Hannesson et al, 2004; Hotte et al, 2005). At the standard delay of $45 \mathrm{~min}$, pretreatment with D-GOV disrupted TORM, consistent with effects observed with a DA-D1 agonist in a test of delayed win-shift responding (Floresco and Phillips, 2001). In contrast, extension of the delay interval of the test from the standard period of $45 \mathrm{~min}$ to $240 \mathrm{~min}$, caused an impairment in TORM that was rescued by pretreatment with D-GOV before the recall test. Collectively, these data show that D-GOV suppresses the expression of TORM under conditions where the memory is expressed ( $45 \mathrm{~min})$, but facilitates the recall of TORM when impaired (240-min delay). This pattern closely resembles effects seen previously with DA-D1 agonists that impair working memory performance under optimal conditions while improving impaired performance in tasks dependent on the mPFC (Seamans et al, 1998). Moreover, these data are consistent with the hypothesis that optimal concentrations of DA are essential for executive functions mediated by the MPFC, and that these aspects of cognition are impaired when DA fluctuates below or above these optimal values (Mattay et al, 2003; Phillips et al, 2004). Importantly, this explanation also suggests that the elevation of DA efflux induced by D-GOV may rescue impaired cognitive functions associated with suboptimal DA functions, but suggests that D-GOV could interfere with working memory or temporal order memory function in situations where DA is functioning optimally.

Further evidence for beneficial effects of D-GOV on impaired memory performance is provided by a reduction of working memory errors in the delayed win-shift task. Notably, L-GOV did not improve cognitive performance on this task. These data are consistent with our previous observation of improved recall with D,L-GOV under conditions of impaired working memory (Lapish et al, 2012) and further separate the effects of D-GOV from L-GOV with respect to improvements in impaired memory function.

Although both D-GOV and L-GOV maintain high affinity for the DA-D1 receptor, neither appear to act as a direct agonist at this receptor (Figure 1a; Lapish et al, 2012).
Although the current study recommends further exploration of $\mathrm{D}-\mathrm{GOV}$ as a potential intervention to improve impairments in cognitive function observed in schizophrenia, a number of pharmacotherapies that target the DA system have not provided consistent improvement in cognitive function in human subjects. D-GOV, however, may provide a novel approach to targeting the DA system given its unique ability to selectively increase DA efflux in the PFC, but not in the NAc. Increases in PFC DA efflux, by mechanisms yet to be specified, and not a direct action on DA receptors, may explain the bidirectional effects observed on TORM at short- and long-delay intervals and improved radial-arm maze performance.

Pre-synaptic modulation of PFC DA efflux, as opposed to a direct action on DA receptors, may explain the bidirectional effects observed on TORM at short- and long-delay intervals, and improved radial-arm maze performance. COMT inhibitors maintain relative selectivity for the PFC and hippocampal DA system via blocking the metabolism and reuptake of DA in conjunction with a behavioral event such as feeding or a pharmacological challenge (Lapish et al, 2009; Tunbridge et al, 2004). Importantly, in the current study treatment with D-GOV alone was sufficient to increase DA efflux in the PFC, but not NAc, and to our knowledge this is the first time a compound has been identified with this profile. These data separate the effects of D-GOV from L-GOV with respect to improvements in impaired working memory and prospective memory and recommend further investigation of its therapeutic potential in the treatment of cognitive impairment associated with schizophrenia and other neuropsychiatric disorders (Goldman-Rakic et al, 2004).

\section{FUNDING AND DISCLOSURE}

This work was supported by grants from the Canadian Institutes of Health Research (AGP); and the Brain and Behavior Foundation (CCL). Panora Pharmaceuticals provided salary support to DMA. AGP served until July 2013 on the board of directors of Allon Therapeutics. AGP and CCL declare a patent pending related to the use of $\mathrm{D}$-Govadine (PCT/CA2012/050526). AGP declares a pending patent (PCT/CA2004/001813) for an IV formulation of the interference peptide Tat-GluA23Y. The remaining authors declare no conflict of interest.

\section{ACKNOWLEDGEMENTS}

We wish to thank Maureen M Timm, Griffin J Fitzgerald, and Kitty So for technical assistance. This research was inspired by many discussions with Dr James Miller.

\section{REFERENCES}

Agranat II, Caner H (1999). Intellectual property and chirality of drugs. Drug Discov Today 4: 313-321.

Ahn K-C, Bernier BE, Harnett MT, Morikawa H (2010). IP3 receptor sensitization during in vivo amphetamine experience enhances NMDA receptor plasticity in dopamine neurons of the ventral tegmental area. J Neurosci 30: 6689-6699.

Andreasen NC (2000). Schizophrenia: the fundamental questions. Brain Res Brain Res Rev 31: 106-112. 
Bingham B, Jones PG, Uveges AJ, Kotnis S, Lu P, Smith VA et al (2007). Species-specific in vitro pharmacological effects of the cannabinoid receptor 2 (CB2) selective ligand AM1241 and its resolved enantiomers. Br J Pharmacol 151: 1061-1070.

Bunney WE Jr, Hetrick WP, Bunney BG, Patterson JV, Jin Y, Potkin SG et al (1999). Structured interview for assessing perceptual anomalies (SIAPA). Schizophr Bull 25: 577-592.

De Camp WH (1989). The FDA perspective on the development of stereoisomers. Chirality 1: 2-6.

Chambers RA, Sentir AM, Engleman EA (2010). Ventral and dorsal striatal dopamine efflux and behavior in rats with simple vs comorbid histories of cocaine sensitization and neonatal ventral hippocampal lesions. Psychopharmacology (Berl) 212: 73-83.

Dong ZJ, Chen LJ, Jin GZ, Creese I (1997). GTP regulation of (-)stepholidine binding to $\mathrm{R}(\mathrm{H})$ of $\mathrm{D} 1$ dopamine receptors in calf striatum. Biochem Pharmacol 54: 227-232.

Dreher JC, Banquet JP, Allilaire JF, Paillère-Martinot ML, Dubois B, Burnod Y (2001). Temporal order and spatial memory in schizophrenia: a parametric study. Schizophr Res 51: 137-147.

Ferrari G, Yan CY, Greene LA (1995). N-acetylcysteine (D- and L-stereoisomers) prevents apoptotic death of neuronal cells. J Neurosci 15: 2857-2866.

Fibiger HC, Carter DA, Phillips AG (1976). Decreased intracranial self-stimulation after neuroleptics or 6-hydroxydopamine: evidence for mediation by motor deficits rather than by reduced reward. Psychopharmacology (Berl) 47: 21-27.

Floresco SB, Phillips AG (2001). Delay-dependent modulation of memory retrieval by infusion of a dopamine D1 agonist into the rat medial prefrontal cortex. Behav Neurosci 115: 934-939.

Freedman R (2003). Schizophrenia. N Engl J Med 349: 1738-1749. Goldman-Rakic PS, Castner SA, Svensson TH, Siever LJ, Williams GV (2004). Targeting the dopamine D1 receptor in schizophrenia: insights for cognitive dysfunction. Psychopharmacology (Berl) 174: 3-16.

Goldman-Rakic PS, Muly EC 3rd, Williams GV (2000). D(1) receptors in prefrontal cells and circuits. Brain Res Brain Res Rev 31: 295-301.

Gorelova N, Mulholland PJ, Chandler LJ, Seamans JK (2012). The glutamatergic component of the mesocortical pathway emanating from different subregions of the ventral midbrain. Cereb Cortex 22: 327-336.

Hannesson DK, Vacca G, Howland JG, Phillips AG (2004). Medial prefrontal cortex is involved in spatial temporal order memory but not spatial recognition memory in tests relying on spontaneous exploration in rats. Behav Brain Res 153: 273-285.

Hofer A, Bodner T, Kaufmann A, Kemmler G, Mattarei U, Pfaffenberger NM et al (2011). Symptomatic remission and neurocognitive functioning in patients with schizophrenia. Psychol Med 41: 2131-2139.

Hotte M, Naudon L, Jay TM (2005). Modulation of recognition and temporal order memory retrieval by dopamine D1 receptor in rats. Neurobiol Learn Mem 84: 85-92.

Jin G-Z, Zhu Z-T, Fu Y (2002). (-)-Stepholidine: a potential novel antipsychotic drug with dual D1 receptor agonist and D2 receptor antagonist actions. Trends Pharmacol Sci 23: 4-7.

Kapur S, Agid O, Mizrahi R, Li M (2006). How antipsychotics workfrom receptors to reality. Neurorx J Am Soc Exp Neurother 3: 10-21.

Lapish CC, Ahn S, Evangelista LM, So K, Seamans JK, Phillips AG (2009). Tolcapone enhances food-evoked dopamine efflux and executive memory processes mediated by the rat prefrontal cortex. Psychopharmacology (Berl) 202: 521-530.
Lapish CC, Belardetti F, Ashby DM, Ahn S, Butts KA, So K et al (2012). A preclinical assessment of d.l-govadine as a potential antipsychotic and cognitive enhancer. Int J Neuropsychopharmacol 15: 1441-1455.

Mattay VS, Goldberg TE, Fera F, Hariri AR, Tessitore A, Egan MF et al (2003). Catechol O-methyltransferase val158-met genotype and individual variation in the brain response to amphetamine. Proc Natl Acad Sci USA 100: 6186-6191.

Moghaddam B, Bunney BS (1990). Acute effects of typical and atypical antipsychotic drugs on the release of dopamine from prefrontal cortex, nucleus accumbens, and striatum of the rat: an in vivo microdialysis study. J Neurochem 54: 1755-1760.

Moser PC, Hitchcock JM, Lister S, Moran PM (2000). The pharmacology of latent inhibition as an animal model of schizophrenia. Brain Res Brain Res Rev 33: 275-307.

Natesan S, Reckless GE, Barlow KBL, Odontiadis J, Nobrega JN, Baker GB et al (2008). The antipsychotic potential of 1-stepholidine-a naturally occurring dopamine receptor D1 agonist and D2 antagonist. Psychopharmacology (Berl) 199: 275-289.

Phillips AG, Ahn S, Floresco SB (2004). Magnitude of dopamine release in medial prefrontal cortex predicts accuracy of memory on a delayed response task. J Neurosci 24: 547-553.

Robaa D, Enzensperger C, Eldin Abulazm S, Hefnawy MM, El-Subbagh HI, Wani TA et al (2011). Chiral indolo[3,2f][3]benzazecine-type dopamine receptor antagonists: synthesis and activity of racemic and enantiopure derivatives. J Med Chem 54: 7422-7426.

Sams-Dodd F, Lipska BK, Weinberger DR (1997). Neonatal lesions of the rat ventral hippocampus result in hyperlocomotion and deficits in social behaviour in adulthood. Psychopharmacology (Berl) 132: 303-310.

Seamans JK, Floresco SB, Phillips AG (1998). D1 receptor modulation of hippocampal-prefrontal cortical circuits integrating spatial memory with executive functions in the rat. J Neurosci 18: 1613-1621.

Truitt WA, Johnson PL, Dietrich AD, Fitz SD, Shekhar A (2009). Anxiety-like behavior is modulated by a discrete subpopulation of interneurons in the basolateral amygdala. Neuroscience 160: 284-294.

Tseng KY, Chambers RA, Lipska BK (2009). The neonatal ventral hippocampal lesion as a heuristic neurodevelopmental model of schizophrenia. Behav Brain Res 204: 295-305.

Tunbridge EM, Bannerman DM, Sharp T, Harrison PJ (2004). Catechol-o-methyltransferase inhibition improves set-shifting performance and elevates stimulated dopamine release in the rat prefrontal cortex. J Neurosci 24: 5331-5335.

Uggerby P, Nielsen RE, Correll CU, Nielsen J (2011). Characteristics and predictors of long-term institutionalization in patients with schizophrenia. Schizophr Res 131: 120-126.

Weiner I, Arad M (2009). Using the pharmacology of latent inhibition to model domains of pathology in schizophrenia and their treatment. Behav Brain Res 204: 369-386.

Weiner I, Feldon J (1997). The switching model of latent inhibition: an update of neural substrates. Behav Brain Res 88: 11-25.

Weiner I, Schiller D, Gaisler-Salomon I (2003). Disruption and potentiation of latent inhibition by risperidone: the latent inhibition model of atypical antipsychotic action. Neuropsychopharmacology 28: 499-509.

Zhai H, Miller J, Sammis G (2012). First enantioselective syntheses of the dopamine D1 and D2 receptor modulators, $(+)$ - and ( - )-govadine. Bioorg Med Chem Lett 22: 1557-1559.

Supplementary Information accompanies the paper on the Neuropsychopharmacology website (http://www.nature.com/npp) 